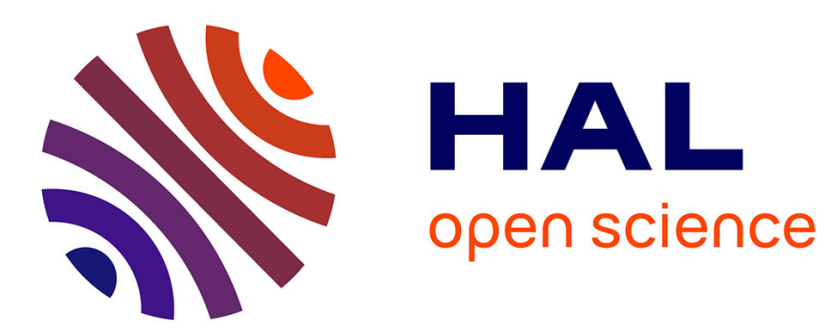

\title{
Blue Tits Use Fledgling Quantity And Quality As Public Information In Breeding Site Choice
}

\author{
Deseada Parejo, Joël White, Jean Clobert, Amelie Dreiss, Etienne G. J.
} Danchin

\section{- To cite this version:}

Deseada Parejo, Joël White, Jean Clobert, Amelie Dreiss, Etienne G. J. Danchin. Blue Tits Use Fledgling Quantity And Quality As Public Information In Breeding Site Choice. Ecology, 2007, 88 (9), pp.2373-2382. 10.1890/06-2000.1 . hal-02096809

\section{HAL Id: hal-02096809 https://hal.science/hal-02096809}

Submitted on 2 Apr 2021

HAL is a multi-disciplinary open access archive for the deposit and dissemination of scientific research documents, whether they are published or not. The documents may come from teaching and research institutions in France or abroad, or from public or private research centers.
L'archive ouverte pluridisciplinaire HAL, est destinée au dépôt et à la diffusion de documents scientifiques de niveau recherche, publiés ou non, émanant des établissements d'enseignement et de recherche français ou étrangers, des laboratoires publics ou privés. 


\title{
BLUE TITS USE FLEDGLING QUANTITY AND QUALITY AS PUBLIC INFORMATION IN BREEDING SITE CHOICE
}

\author{
Deseada Parejo, ${ }^{1,5}$ Joel White, ${ }^{2} \mathrm{Jean}_{\text {Clobert }}{ }^{3}$ Amelie Dreiss, ${ }^{4}$ and Etienne Danchin ${ }^{2}$ \\ ${ }^{1}$ Estación Experimental de Zonas Áridas, CSIC, C/General Segura, 1, 04001 Almería, Spain \\ ${ }^{2}$ Evolution et Diversité Biologique (EDB), UMR CNRS-UPS 5174, Université Paul Sabatier - Toulouse III, 118 Route de Narbonne, \\ Bat IV R3, 31062 Toulouse Cedex 9, France \\ ${ }^{3}$ Station d'Ecologie Expérimentale du CNRS, Laboratoire Evolution et Diversité Biologique, Moulis, 09200 Saint-Girons, France \\ ${ }^{4}$ Laboratoire de Fonctionnement et Évolution des Systèmes Écologiques, Université Pierre et Marie Curie, CNRS-UMR 7625, \\ 7 quai St-Bernard, Bât. A, $7^{\mathrm{e}}$ étage, Case 237, F-75252 Paris Cedex 05, France
}

\begin{abstract}
Public information (PI), which is the information that can be derived from the behavior and performance of conspecifics, has been demonstrated to be used in many fitnessenhancing decisions. In the context of breeding habitat choice, PI use has been called "habitat copying." We experimentally tested the existence of habitat copying in the Blue Tit (Cyanistes caeruleus), a nonmigratory, short-lived hole-nesting bird. We manipulated the mean number of fledglings raised locally (quantity) and their condition (quality) as components of PI by transferring nestlings from Decreased (D) patches to Increased (I) patches. Our manipulations caused a negative relationship between fledgling quantity and quality that does not exist naturally: I patches had a higher number of fledglings that were in poorer condition, whereas $\mathrm{D}$ patches had a lower number in better condition. Control (C) patches, whether manipulated or not, had intermediate levels in terms of fledgling quantity and quality. Adult emigration the following year was higher from D than from C or I patches. Similarly, adult dispersal distance decreased for individuals coming from $\mathrm{D}$ to $\mathrm{C}$ to I patches. This suggests that resident breeders rely mainly on fledgling quantity to make emigration decisions. Emigration patterns of juveniles did not vary in relation to our patch manipulation. Immigration rates were higher and similar in I and D patches than in C patches. Hence, immigrant Blue Tits seem to rely on one of the manipulated components of PI and are insensitive to the discrepancy between fledgling quantity and quality. This shows that even nonmigratory species, such as Blue Tits, may use PI in their dispersal decisions but weigh its components differently for emigration and immigration. Differences among species in the importance of PI in breeding habitat choices may be explained by differences in life histories.
\end{abstract}

Key words: birds; Blue Tit; breeding habitat selection; components of public information; Cyanistes caeruleus; dispersal; emigration; habitat copying; immigration; performance-based cues; resident birds.

\section{INTRODUCTION}

Public information (hereafter termed PI), that is, information extracted from the behavior and performance of others (Danchin et al. 2001, Danchin et al. 2004), has a prominent role in many fitness-enhancing decisions (Valone and Templeton 2002, reviewed in Danchin et al. 2004). Whenever the environment varies, individuals indeed need to acquire information on the environment to make optimal choices. PI provides an estimate of environmental quality by indicating where and when others achieve the highest success, thus diminishing uncertainty.

The importance of any choice depends on the reliability of the information that is used to make the decision. PI is not delivered intentionally in the sense that it does not bring direct benefits to the information

Manuscript received 30 November 2006; revised 31 January 2007; accepted 6 February 2007. Corresponding Editor: W. D. Koenig.

${ }^{5}$ E-mail: parejo@eeza.csic.es producers. It is collected by bystanders that may monitor others interacting with their environment to extract information about this environment. PI is thus a form of information extracted from cues that are inadvertently produced by information producers, a category of information termed inadvertent social information (Danchin et al. 2004). Since individuals are selected to perform as well as possible, PI may not be falsified easily and is thus reliable. PI use has been shown to be beneficial in choices of foraging patches (Templeton and Giraldeau 1995, Coolen et al. 2003), breeding sites (Deutsch 1992, Danchin et al. 1998, Brown et al. 2000, Doligez et al. 2002, Parejo et al. 2005, Ward 2005), host nests in brood parasites (Pöysä 2006), and mates (Nordell and Valone 1998, Gros-Louis et al. 2003) in many animal taxa.

Public information may provide advantages to individuals even in the case of conflicting information from different sources. For instance, foraging ninespined sticklebacks (Pungitius pungitius) prefer patches in which other foragers have a high feeding success over 
those in which there are many foragers, i.e., PI is preferentially used rather than local number of conspecifics (Coolen et al. 2005). Moreover, the conflict between personal and public information is solved in favor of PI whenever personal information is not updated, costly to acquire, or inconsistent through years (Templeton and Giraldeau 1996, Kendal et al. 2004, van Bergen et al. 2004). However, PI is sometimes unavailable either in time or in space. For instance, individuals may be constrained from gathering information in distant patches. Also, in a context of breeding habitat choice, breeders and juveniles may not be able to gather local reproductive success of conspecifics, especially in highly synchronous breeding species, because breeding success is only measurable at the end of a breeding period (Boulinier et al. 1996). Furthermore, under some circumstances, PI may provide no benefits or even entail some cost, for instance by the occurrence of informational cascades (Giraldeau et al. 2002). These facts may make PI use unsuitable (e.g., Sterna nilotica, Erwin et al. 1998; Turdus merula, Smith et al. 2001; Gasterosteus aculeatus, Coolen et al. 2003; Falco naumanni, Serrano and Tella 2003). Conceivably, the use of PI, although often profitable, may differ among situations and phenotypes.

The use of PI in breeding habitat selection has been termed "habitat copying" (Wagner and Danchin 2003, Danchin et al. 2004), as it leads animals to copy the habitat choices of successful conspecifics. In birds, habitat copying seems to be particularly prevalent among colonial species because the performance of many conspecifics may be observed simultaneously, thus providing good estimates of local habitat quality (Danchin et al. 2001, Valone and Templeton 2002). Open-nesting species are also more likely to use PI than hole-nesting species because prospecting individuals may gather information from a distance, which diminishes the cost of prospecting (Danchin et al. 1998). Nevertheless, some of the evidence supporting habitat copying comes from territorial hole-nesting species (e.g., Collared Flycatchers (Ficedula albicollis); Doligez et al. 1999, 2002) and secondary hole nesters, e.g., Eurasian Kestrel Falco tinnunculus and the roller Coracias garrulus (Parejo et al. 2005). In addition, migratory species may be more likely to use PI than resident species because the former species are time limited in their assessment of habitat quality. This shorter time window should lead them to value integrative cues such as PI. Resident species, on the other hand, may access other more direct cues revealing habitat quality during the whole winter, and particularly just before reproduction.

So far, experimental evidence for habitat copying has only been provided for the Collared Flycatcher, a migratory, hole-nesting passerine (Doligez et al. 2002). Correlations, although suggestive, cannot unambiguously provide support to the use of PI because this and other cues indicating habitat quality are likely to be correlated (Doligez et al. 2002, Valone and Templeton
2002). Thus, in correlative studies, the relative use of PI and other correlated cues is difficult to disentangle.

In this study we performed a similar experiment to that of Doligez et al. (2002) but with a nonmigratory passerine, the Blue Tit (Cyanistes caeruleus). This is only the second experimental test of habitat copying and the first time with a nonmigratory bird. Because PI is expected to have a lower influence in resident than in migratory species, results supporting habitat copying in nonmigratory birds would suggest that habitat copying is a widespread strategy. We thus manipulated PI to test whether it is really used in Blue Tits. For this, we manipulated the local reproductive success in one year at the scale of patches (patch reproductive success, mean number of fledged chicks per patch) in a natural population via brood size manipulations. Patches were either (1) manipulated to decrease their mean reproductive success (decreased, D), (2) not manipulated (unmanipulated control), (3) manipulated by cross-fostering chicks (exchanging chicks from one nest to another) between nests inside the same patch or within patches of the same treatment, thus leaving the patch reproductive success unchanged (manipulated control), or (4) manipulated to increase the local mean reproductive success (increased, I).

We first tested the efficacy of our manipulations in modifying the average breeding performance of Blue Tits per patch. We then tested the basic prediction that, in the following year, Blue Tits would prefer to breed (i.e., recruit into and/or remain in) in I compared to control patches and in control compared to $\mathrm{D}$ patches. Our experiment is likely to produce a negative correlation between fledgling quantity and quality (as in Doligez et al. 2002) not normally appearing in natural conditions because the addition or removal of three nestlings represents an increase or a decrease of $26.52 \%$ in brood size (mean clutch size in the population $=11.31$ eggs). Therefore, parents of enlarged broods are expected to raise more chicks that will be in worse condition than parents of reduced broods.

The quantity and quality of newly fledged individuals are two components of PI, as they both reveal local breeding performance. Under the assumption that our manipulations generated a negative relationship between the quantity and quality of juveniles produced in our study patches (as this was the case in Doligez et al. 2002), there were four possibilities: (1) individuals might rely only on the number of fledglings produced; (2) alternatively, they may rely only on their quality; they may also account for both components simultaneously and either (3) ignore the inconsistency between the two types of information or (4) give more weight to the situations in which the two types of information are consistent than those in which the two types of information are inconsistent.

In the first case, we expect a preference for I over control over D patches. In the second case, we expect the opposite trend. In the third case, preference is expected 
to be higher for both I and D patches relative to control patches. In the fourth case, we expect tits to prefer control patches over both I and D patches.

\section{Materials And Methods \\ Study system}

The experiment was conducted during the spring of 2003 and its effects observed during the spring of 2004 in a 500-ha portion of a mixed deciduous forest of the Parc Régional de la Forêt d'Orient in central France (Aube, $48^{\circ} 17^{\prime} \mathrm{N}, 4^{\circ} 17^{\prime} \mathrm{E}$ ). The study area is well isolated from other possible breeding areas by a lake on one side and areas of cultivated fields with no suitable breeding habitat on the other sides (Fig. 1). The nearest forest patch outside our system was $4000 \mathrm{~m}$ away. The main tree species in the forest are oaks (Quercus petraea) and hornbeams (Carpinus betulus). The forest is divided in 50 patches of $8.14 \pm 0.90$ ha each (mean \pm SD; Fig. 1). Different patches host different stages of forest development in order to be sustainably exploited by the French Office National des Forêts. However, the vegetation did not vary noticeably within patches. Patches were more or less rectangular in shape and were separated by paths at least $3 \mathrm{~m}$ wide. There were 759 nest boxes evenly distributed over the study area in 1999, resulting in 31 patches containing an average of $24.48 \pm 0.52$ nest boxes each (mean \pm SD; Fig. 1). Blue and Great Tits (Parus major) commonly used such nest boxes, although the Blue Tit was the most common species (53.3\% of the occupied nest boxes held were by Blue Tits vs. $42.7 \%$ by Great Tits). There were unused boxes in all patches during the study period.

The Blue Tit is a small $(\sim 11 \mathrm{~g})$, socially monogamous hole-nesting passerine, common in the woodlands in Europe (Cramp and Perrins 1993). In the study area, Blue Tits are mostly sedentary (recaptures have been made during the winter), and a small proportion of the population makes a second breeding attempt after successfully raising a first brood (Parejo and Danchin 2006). The mean clutch size in first clutches was 11.31 eggs (range $=5-17, N=228$ ). Only the female incubates the eggs and broods the young, and both sexes feed and clean them. The nestling period lasts $16-20 \mathrm{~d}$ and the young reach independence around two weeks after fledging.

\section{Public information manipulation}

We manipulated public information at the patch scale by moving three two-day-old nestlings between pairs of nests (matched by hatching dates) from nests in patches assigned to the $\mathrm{D}$ treatment to nests in patches assigned to the I treatment. In addition, nestlings were crossfostered between pairs of nests of patches assigned to the manipulated control treatment. At the beginning of 2003, each patch was randomly assigned (see spatial distribution of the treatments in Fig. 1) to one of the following treatments: (1) patches with decreased patch reproductive success $(\mathrm{D}, N=10)$, in which the mean

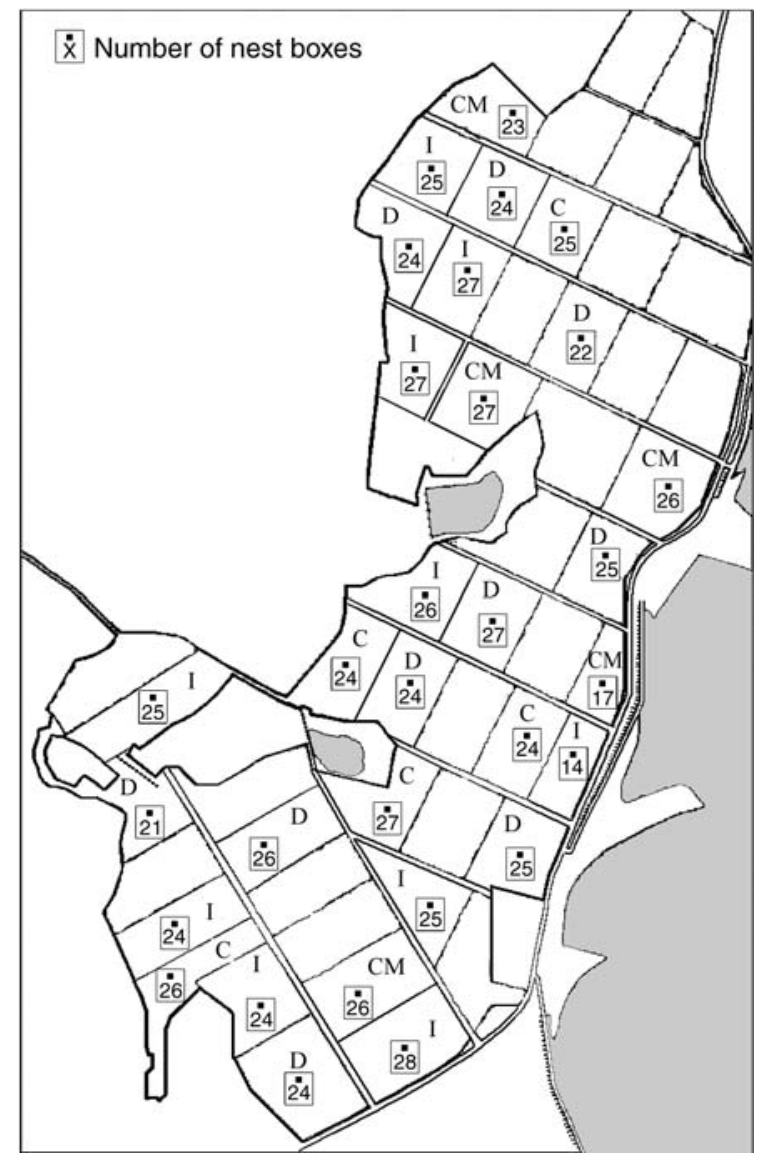

FIG. 1. Map of the study area with the 31 nest-box patches. Numbers within squares indicate the number of nest boxes present in that study patch. Patches with no data for number of nest boxes are wooded patches with no nest boxes. Dotted areas indicate water. The remaining land is unsuitable for Blue Tit breeding (cultivated fields). Experimental treatments are: D, decreased patches; C, unmanipulated control patches; CM, manipulated control patches; I, increased patches.

success of $51 \%(N=25)$ of the nests was reduced by removing three nestlings that were then added to recipient nests in I patches. (2) Unmanipulated control patches $(N=6)$, in which no manipulation was performed and the natural patch reproductive success remained unchanged. (3) Manipulated control patches $(N=5)$, in which a mean of $38 \%(N=8)$ of the nests had cross-fostered chicks from nests of either the same or other patches assigned to the same Manipulated control treatment. This manipulation should not lead to any change in patch reproductive success. (4) Patches with increased patch reproductive success (I, $N=10$ ), in which the mean success of $49 \%(N=25)$ of the nests was increased by the addition of three nestlings coming from reduced nests. All patches thus included unmanipulated nests so that it was possible to separate the relative impact of manipulations at the scale of the individuals from that of manipulations at the scale of the patch. 
Experimental manipulations were carried out between the two days after the first hatching and the end of the hatching peak.

\section{Reproductive data and conventions}

In both years, nest boxes were inspected regularly from nest building (early April) to fledging to determine reproductive parameters and compute emigration and immigration rates. Adults were captured, measured, and ringed or identified in the nest box when chicks were from 8 to $13 \mathrm{~d}$ old and chicks ringed when $13 \mathrm{~d}$ old. Measurements taken were body mass (measured with a Pesola spring balance with a precision of $0.1 \mathrm{~g}$ ) and tarsus length (measured with a sliding caliper to the nearest $0.1 \mathrm{~mm}$ ). Adults were sexed according to the presence or absence of a brood patch. In the breeding season of 2003, we captured 241 adult Blue Tits, which corresponded to $86.7 \%$ of the breeders that raised chicks until the age of 8 days, and we marked 1286 juveniles, which corresponded to $100 \%$ of the chicks that survived until the ringing age. From these marked individuals, only 74 (39 adults and 35 juveniles) were recaptured breeding in 2004, the year in which we captured $66.3 \%$ of the breeding adults (with 8-day-old chicks). Mortality rates for this species are high; for instance, in Britain mortality ranges from 51-62\% (Dhondt et al. 1998). Therefore, in spite of the low apparent local return rate, an important fraction of the population seems to be engaged in the patterns that we analyzed here. The adult capture effort in 2003, measured as the probability of each breeder to be captured, did not differ among treatments (Logistic regression model: treatment effect, $\left.\chi_{3}^{2}=6.25, P=0.10\right)$. Dispersal distance between the nest boxes used in the two consecutive years was estimated by registering the UTM coordinate of every nest box determined by GPS (Global Positioning System). Positions were recorded only when the error was $<5 \mathrm{~m}$.

Emigration was quantified by two variables: the emigration probability between patches in the two consecutive years as a binary variable (resident vs. emigrant) and the dispersal distance between subsequent nest boxes. Despite the fact that data on individual dispersal distance could be skewed if many individuals disperse very far, we considered this measure in our emigration analyses because (1) the study area was big (500 ha) and quite isolated, and these facts reduce dispersal. Thus, dispersal seems more likely to occur inside that outside the study area, and (2) it is important to understand the dynamic of birds dispersing inside the study area and mainly to know the effect of PI on them, even in the case that some birds disperse far from the study area.

The immigration rate was computed as the ratio of the number of immigrants into a patch (number of breeders in the patch minus the faithful breeders) to the number of nest boxes that were available to Blue Tits (nest boxes not previously occupied by insects or small mammals).
Tit density was computed for each patch as the proportion of nest boxes occupied by tits. This was realistic because patches had approximately the same dimensions and nest box density. Whenever patch dimension varied, nest box density varied in parallel.

A nest box was considered as occupied when egg laying began, and we only considered first clutches in these analyses. We thought that second clutches were not likely to be important in the habitat selection process because only a small fraction of the population undertakes them ( $\sim 7 \%$ of breeders). Consequently, although the gathering process is likely to occur late in the breeding season, we would expect birds to prospect before the end of first clutches because, otherwise, information available would be of low value.

\section{Statistical analyses}

Analyses were performed using SAS statistical software. We first tested the natural relationship between fledgling quantity and quality in unmanipulated nests from all the patches, irrespective of the patch treatment, by performing a General Linear Mixed Model (MIXED SAS procedure). In this model the mass of each chick was introduced as the dependent variable and the age of the chick, chick tarsus length and the number of chicks in the nest as predictors. Since in this analysis each chick was used as a statistically independent event, the nest was introduced as a random effect to account for the fact that chicks from the same nest are not independent.

Then the effect of the treatment at the level of the patch on fledging quality and quantity was investigated. A General Linear Mixed Model (MIXED SAS procedure) was performed to test the effect of the treatment on chick body condition, introducing the chick mass as the dependent variable, the chick tarsus length and the age of the brood as predictors, and the treatment as a factor. The nest was introduced as a random effect in this analysis to account for the fact that chicks from the same nest are not independent. The effect of the treatment on fledging quantity was analyzed by using a one-way ANOVA model (GLM SAS procedure) in which the number of fledglings per nest was the dependent variable and the treatment the factor.

The effect of the treatment on the emigration process was studied by performing (1) logistic regression models with logit-link function and binomial distribution (GENMOD SAS procedure) in which the probability of each individual to emigrate from a patch between years $t$ and $t+1$ was the dependent variable, (2) ANCOVA models (GLM SAS procedure) in which the log-transformed dispersal distance for each individual was the dependent variable. In these analyses, the sex of the individual was introduced as a factor to account for the fact that sex is known to affect dispersal decisions (Greenwood 1980) and tit density (arcsin transformed) as a predictor in order to take into account that population density is one of the factors affecting animal dispersal decisions (see review in Clobert et al. 2001). 
Moreover, in these models either the treatment performed on the nest or the individual reproductive success (failure vs. success) was introduced to account for the effect of personal information, which is likely to be preferentially used when compared with public information (Templeton and Giraldeau 1996, Kendal et al. 2004, van Bergen et al. 2004). Finally, we introduced the mean patch reproductive success of Great Tits in the models to address the possible interaction between Blue and Great Tits. Because these two species are competitors (Perrins 1979, Wilson 1992), they may affect the other species either negatively (for instance by depleting food resources) or positively (by providing valuable heterospecific public information; Parejo et al. 2005).

The effects of the treatment on both the individual emigration probability and dispersal distance were studied separately for juveniles and adults because factors affecting natal and breeding dispersal are likely to differ (Clobert et al. 2001). Although adults and chicks from the same nests may not be statistically independent events, we considered them as independent in the emigration analysis because all the individuals recaptured in 2004 came from 55 different nests and no bird coming from a specific nest, either adult or juvenile, went to the same nest as its partner, offspring, siblings, or parents.

An ANCOVA model (GLM SAS procedure) was used to test for the effect of the experimental treatment on the immigration rate to a patch. The experimental treatment was introduced in the model as a factor and tit density (arcsine transformed) and mean patch reproductive success of Great Tits as covariables.

Statistical significance was set at $P<0.05$, but for model selection, variables with $P<0.1$ were retained.

\section{Results}

\section{Effect of the PI manipulation on chick number and condition}

Mean chick body mass was affected by the experimental manipulation $\left(F_{3,1023}=3.96, P=0.008\right.$; Fig. 2a) once we controlled for the effect of tarsus length $\left(F_{1,1023}\right.$ $=2230.72, P<0.0001)$, age of chicks $\left(F_{1,1023}=13.93, P\right.$ $=0.0002)$ and the random effect of the nest $(Z=6.33, P$ $<0.0001)$. Mean body condition of Blue Tit chicks was significantly higher in decreased (D) patches (where around half of the nests had artificially reduced broods) than in increased (I) patches (where around half of the nests had artificially enlarged broods) and in nests in control patches that had chicks of intermediate condition (Fig. 2a). Mean chick body condition did not differ between the two types of control patches $(P=0.54)$. Our experimental manipulation also affected the mean fledgling number per breeding pair per patch (i.e., patch reproductive success; $F_{3,193}=5.48, P=0.001$; Fig. $2 b$ ): Mean number of fledglings was increased in I patches and decreased in $\mathrm{D}$ patches compared to control patches (Fig. 2b). Mean number of fledglings did not differ


FIG. 2. Effect of the experimental manipulation of public information (PI) in year $t$ on (a) mean chick body condition (quality) and (b) mean number of chicks per nest (quantity). Error bars indicate \pm SE. Chick body condition is computed as the residual of the general linear mixed model performed analyzing the effect of tarsus length, chick capture day, and the random effect of the nest on chick mass. Numbers inside or just above bars are sample sizes of (a) individuals and (b) nests. Only significant pairwise differences are shown, with arrows designating pairs and asterisks indicated significant differences. Neither mean chick body condition $(P=0.54)$ nor mean number of chicks $(P=0.21)$ differed between the two types of control patches. Experimental treatments are: D, decreased patches; NMC, control patches; CM, manipulated control patches; I, increased patches.

$* P<0.05 ; * * P<0.01 ; * * * P<0.001$.

between the two types of control patches $(P=0.21)$. Therefore, since neither the mean body condition nor the mean number of fledglings per patch differed between the two control treatments $(\mathrm{C})$, data from these two treatments were combined for subsequent analyses.

When comparing unmanipulated nests from the four treatments, neither mean chick body condition $\left(F_{3,575}=\right.$ $1.28, P=0.28$, after accounting for tarsus length, age of chicks, and the random effect of nest) nor mean number of fledglings in a patch $\left(F_{3,184}=1.53, P=0.21\right)$ differed among treatments. This shows that the observed differences in measures of public information among treatments when accounting for all nest types simultaneously were only due to our manipulations. Furthermore, our experiment produced a negative relationship between mean body condition and mean number of fledglings that does not exist in natural conditions in the population because we found no relationship between these two variables in unmanipulated nests $\left(F_{1,554}=\right.$ $1.49, P=0.22)$ after controlling for chick age, chick tarsus length, and the random effect of the nest. 
TABLE 1. Summary of results of the effects of the experimental treatment on emigration and immigration of Blue Tits.

\begin{tabular}{|c|c|c|c|c|c|c|c|}
\hline $\begin{array}{l}\text { Dependent variable, } \\
\text { test, and } N\end{array}$ & Independent effects & $\begin{array}{c}\text { Variable } \\
\text { type }\end{array}$ & $\begin{array}{c}\text { Parameter } \\
\text { estimate }\end{array}$ & $\mathrm{df}$ & $\chi^{2}$ & $F$ & $P$ \\
\hline \multirow{5}{*}{$\begin{array}{l}\text { Adult emigration probability; } \\
\text { logistic regression; } 39 \\
\text { individuals }\end{array}$} & treatment & fixed factor & & 2 & 7.67 & & 0.02 \\
\hline & sex & fixed factor & & 1 & 3.14 & & 0.08 \\
\hline & tit density & covariable & -6.97 & 1 & 8.69 & & 0.003 \\
\hline & nest manipulation & fixed factor & & 2 & 2.78 & & 0.25 \\
\hline & $\begin{array}{l}\text { Great Tit patch RS } \\
\text { (reproductive success) }\end{array}$ & covariable & -0.10 & 1 & 0.41 & & 0.52 \\
\hline \multirow{5}{*}{$\begin{array}{l}\text { Adult emigration probability; } \\
\text { logistic regression; } 39 \\
\text { individuals }\end{array}$} & treatment & fixed factor & & 2 & 7.67 & & 0.02 \\
\hline & $\operatorname{sex}$ & fixed factor & & 1 & 3.14 & & 0.08 \\
\hline & tit density & covariable & -6.97 & 1 & 8.69 & & 0.003 \\
\hline & individual RS & fixed factor & & 1 & 0.58 & & 0.45 \\
\hline & Great Tit patch RS & covariable & -0.09 & 1 & 0.34 & & 0.56 \\
\hline Adult dispersal distance; & treatment & fixed factor & & 2,31 & & 2.88 & 0.07 \\
\hline \multirow[t]{4}{*}{ ANCOVA; 36 individuals } & sex & fixed factor & & 1,33 & & 13.14 & 0.001 \\
\hline & tit density & covariable & -1.02 & 1,33 & & 7.23 & 0.01 \\
\hline & nest manipulation & fixed factor & & 2,28 & & 0.16 & 0.85 \\
\hline & Great Tit patch RS & covariable & 0.01 & 1,30 & & 0.26 & 0.62 \\
\hline Adult dispersal distance; & treatment & fixed factor & & 2,30 & & 3.58 & 0.04 \\
\hline \multirow[t]{4}{*}{ ANCOVA; 36 individuals } & sex & fixed factor & & 1,30 & & 10.35 & 0.003 \\
\hline & tit density & covariable & -1.53 & 1,30 & & 14.75 & 0.0006 \\
\hline & individual RS & fixed factor & & 1,30 & & 4.15 & 0.05 \\
\hline & Great Tit patch RS & covariable & 0.02 & 1,29 & & 0.64 & 0.43 \\
\hline \multirow{5}{*}{$\begin{array}{l}\text { Juvenile dispersal } \\
\text { probability; logistic } \\
\text { regression; } 35 \text { individuals }\end{array}$} & treatment & fixed factor & & 2 & 4.01 & & 0.13 \\
\hline & $\operatorname{sex}$ & fixed factor & & 1 & 0.25 & & 0.62 \\
\hline & tit density & covariable & 21.95 & 1 & 2.14 & & 0.14 \\
\hline & nest manipulation & fixed factor & & 2 & 0.03 & & 0.98 \\
\hline & Great Tit patch RS & covariable & 0.43 & 1 & 4.69 & & 0.03 \\
\hline \multirow{5}{*}{$\begin{array}{l}\text { Juvenile dispersal distance; } \\
\text { ANCOVA; } 34 \text { individuals }\end{array}$} & treatment & fixed factor & & 2,26 & & 0.20 & 0.82 \\
\hline & $\operatorname{sex}$ & fixed factor & & 1,32 & & 13.35 & 0.0003 \\
\hline & tit density & covariable & -0.10 & 1,28 & & 0.05 & 0.82 \\
\hline & nest manipulation & fixed factor & & 2,29 & & 0.68 & 0.51 \\
\hline & Great Tit patch RS & covariable & 0.03 & 1,31 & & 1.87 & 0.18 \\
\hline \multirow{3}{*}{$\begin{array}{l}\text { Local immigration rate; } \\
\text { ANCOVA; } 30 \text { patches }\end{array}$} & treatment & fixed factor & & 2,27 & & 1.88 & 0.17 \\
\hline & tit density & covariable & -0.11 & 1,25 & & 1.38 & 0.25 \\
\hline & Great Tit patch RS & covariable & -0.009 & 1,26 & & 1.90 & 0.18 \\
\hline \multirow{3}{*}{$\begin{array}{l}\text { Local immigration rate; } \\
\text { ANCOVA; } 30 \text { patches }\end{array}$} & treatmentB & fixed factor & & 1,28 & & 3.90 & 0.058 \\
\hline & tit density & covariable & -0.12 & 1,26 & & 1.46 & 0.24 \\
\hline & Great Tit patch RS & covariable & -0.01 & 1,27 & & 1.85 & 0.18 \\
\hline
\end{tabular}

Notes: Starting models are specified in column 1. The final models were obtained by backward elimination, with the stepwise removal of all effects with $P \geq 0.1$. Selected effects in each model are in bold type. Slopes of continuous effects are shown. The variable "treatment" has three categories: D, decreased patches; C, control patches; and I, increased patches. Similarly, the variable "nest manipulation" has three categories: reduced nests, control nests, and enlarged nests. "TreatmentB" was coded as control vs. manipulated. "Individual RS" was categorized as failed vs. successful individuals. In the analyses testing the effect of the treatment on adult emigration either (1) the manipulation performed on the nest or (2) the individual reproductive success was introduced; thus, there are two sets per dependent variable. However, in the case of juveniles, only analyses accounting for the manipulation performed on the nest were performed.

\section{Effect of PI manipulation on emigration}

We found an effect of the age (juvenile vs. adult) of the individual in 2003 on its emigration probability (logistic regression model: $\chi_{1}^{2}=19.43, P<0.0001, N=$ 74 individuals) and on its dispersal distance as well (ANOVA: $F_{1,68}=35.07, P<0.0001, N=70$ individuals). We thus performed separate analyses for each age class.

The emigration probability of adult Blue Tits between year $t$ and $t+1$ differed among patch treatments (Table 1, Fig. 3a). After accounting for the effect of sex and breeding density in the patch in year $t$ (Table 1), adult emigration probability was lower in $\mathrm{C}$ and I patches than in D patches (Fig. 3a). The mean patch reproductive success of Great Tits was not related to the probability of emigration. The manipulation performed on the nest (reduced, enlarged, or unmanipulated broods) did not affect the probability of emigration of the owners of that nest, either (Table 1). Personal breeding success (failure vs. success) did not affect adult emigration probability either when we introduced it in the model instead of the manipulation performed in the nest (Table 1).

Adult dispersal distance differed among experimental patch treatments (Fig. 3b) once we accounted for the effect of sex, patch breeding density in year $t$, and personal breeding success, which led failed individuals $(299.60 \pm 82.98 \mathrm{~m}$ [mean $\pm \mathrm{SE}], N=5)$ to disperse farther than successful ones $(237.26 \pm 57.20 \mathrm{~m}$ [mean \pm $\mathrm{SE}$ ], $N=31$; Table 1). Individuals dispersed farther from $\mathrm{D}$ than I patches, and mean dispersal distance was intermediate in $\mathrm{C}$ patches (Fig. 3b). The mean patch reproductive success of Great Tits was not related to the probability of emigration (Table 1). In the same way as for emigration probability, adult dispersal distance was 

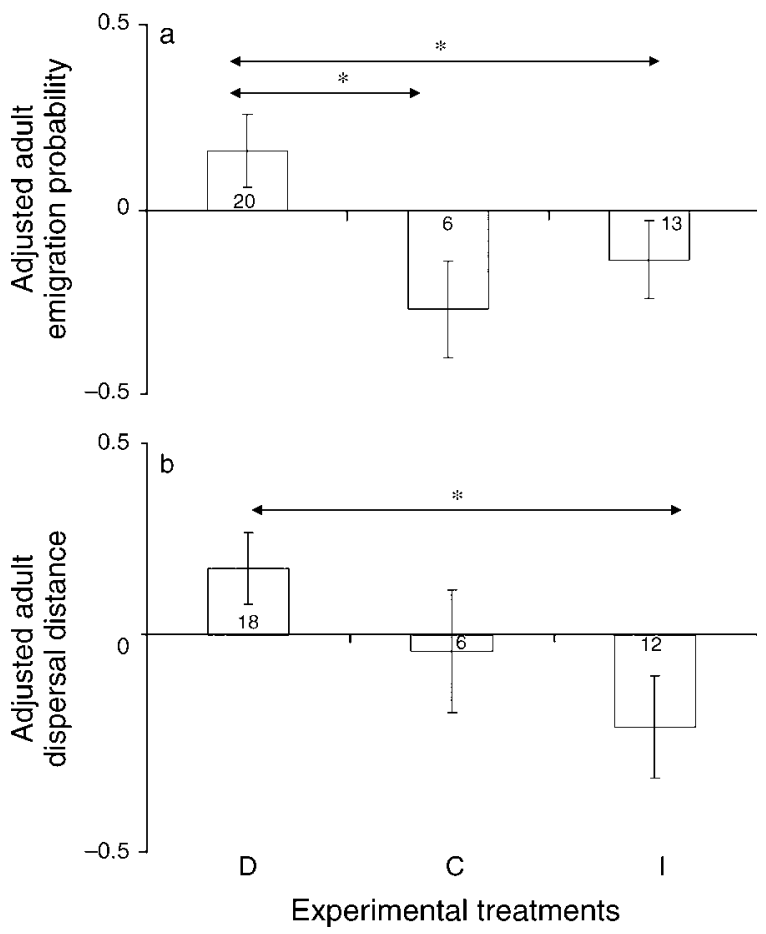

FIG. 3. Emigration pattern of adult Blue Tits in year $t+1$ according to the experimental manipulation of PI performed in year $t$. The $y$-axis represents residuals from (a) the logistic regression of emigration probability on sex and local tit breeding density in year $t$ and (b) an ANCOVA model analyzing the effect of the sex and local tit breeding density in year $t$ on dispersal distance. Data are means \pm SE, and numbers inside bars are sample sizes (individuals). Only significant pairwise differences are shown, with arrows designating pairs and asterisks indicated significant differences: ${ }^{*} P<$ 0.05. Experimental treatments are: $\mathrm{D}$, decreased patches; $\mathrm{C}$, control patches; I, increased patches.

not affected by the actual brood size manipulation experienced by the breeders (Table 1).

In juveniles, emigration probability did not differ among patch treatments (Table 1). Juvenile emigration probability was positively related to mean patch reproductive success of Great Tits. But neither tit density in the natal patch, the manipulation performed on the natal nest, nor the sex of juveniles affected the emigration probability (Table 1).

The dispersal distance of juveniles did not differ according to manipulation, whether performed at the patch or nest scale (Table 1). Neither the density nor the patch reproductive success of Great Tits was related to juvenile dispersal distance. Only the sex effect was significant (Table 1), with females dispersing farther than males (mean dispersal distance of females vs. males, $1356.22 \mathrm{~m}$ vs. $462.72 \mathrm{~m}$ ).

\section{Effect of the PI manipulation on immigration}

Local immigration rates did not differ among treatments and were not related to local tit density or patch reproductive success of Great Tits in year $t$ (Table
1). However, we may see graphically that immigration rates were similar in D and I patches and different from that of $\mathrm{C}$ patches (Fig. 4a). This pattern is expected if individuals use either fledgling quality or quantity in their settlement decisions. In a post hoc test we found that immigration rate differed between $\mathrm{C}$ and $\mathrm{D}+\mathrm{I}$ patches (Fig. 4b) and was not related to local tit density or patch reproductive success of Great Tits in year $t$ (Table 1). Local immigration rate was higher in $\mathrm{D}+\mathrm{I}$ than in $\mathrm{C}$ patches.

\section{Discussion}

Our experiment demonstrated that adult Blue Tits use public information when choosing a breeding habitat. First, adults seem to rely on PI in their emigration decisions. The consistent preference of adult Blue Tits for I patches when analyzing both emigration probability and dispersal distance shows that they are using PI. More concretely, fledgling quantity seems to be important in determining habitat preference because adult Blue Tits left $\mathrm{D}$ more often than I patches and dispersed farther from $D$ patches. Individuals are thus able to evaluate patch reproductive success and decide accordingly.

The use of other cues of habitat quality correlated with the patch reproductive success is not likely since

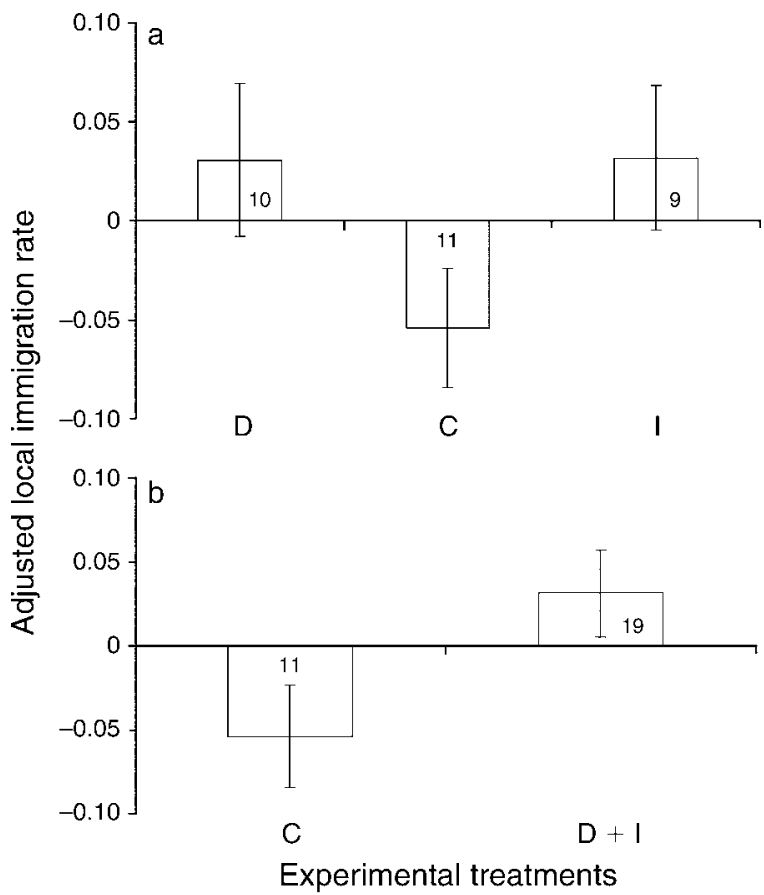

FIG. 4. Local immigration rate of Blue Tits in year $t+1$ according to the experimental manipulation of PI performed in year $t$. The $y$-axis represents residuals from the linear regression of local tit density in year $t$ on immigration rate in $t+1$. Data are means $\pm \mathrm{SE}$, and numbers inside bars are sample sizes (patches). Experimental treatments are: (a) D, decreased patches; C, control patches; I, increased patches; (b) C, control patches; D + I, decreased and increased patches grouped. 
our manipulation broke up the link between patch reproductive success and these other potentially informative cues. The only difference between $\mathrm{D}$ and I patches was thus likely to result from our manipulations of fledgling quality and quantity. Furthermore, these effects of PI on emigration in adult Blue Tits were found after accounting for the potential confounding effects of sex, local breeding density, personal breeding success, and Great Tit patch reproductive success. Indeed, emigration patterns differed between sexes, and emigration was always more likely and over longer distances at low than at high breeding density. This suggests the parallel importance of social attraction in this species as in the only other species in which habitat copying has been demonstrated experimentally (Collared Flycatcher, Doligez et al. 2004b). However, whatever the respective roles of density and fledgling quantity and quality, conspecific density constitutes another component of inadvertent social information, namely the presence of conspecifics in various patches.

It is possible that both types of information, the density and conspecific performance, are used in relation to their availability. While PI is only available during a short period at the end of the breeding season (Boulinier et al. 1996), density can be assessed during the whole breeding season and possibly at the beginning of the following year. Although PI probably constitutes a finer and more accurate cue than density, the second one is probably easier to obtain than PI in hole-nesting species such as Blue Tits. As a consequence, PI may be available only to a small fraction of the individuals in the population, making habitat selection based on density a more ubiquitous strategy.

Personal information seemed to influence only some emigration decisions. The individual reproductive success (coded as failed vs. successful breeders) was related to adult dispersal distance, with failed individuals dispersing farther than successful ones. However, the experimental manipulation performed at the nest level was not related either to the adult probability of emigration or dispersal distance. This may be an artifact of our identification protocol: only breeders with chicks $>8$-days-old were captured. Thus, breeders that failed before that stage were not considered in our analyses, which reduced the amount of variation in personal information that we were able to estimate. This may explain the apparent lack of effect of personal information on some individual decisions.

In contrast to adults, conspecific public information, either as fledgling quality or as quantity, was not a major factor in juvenile habitat selection. Such a difference between juveniles and adults may reflect the different constraints affecting each age class. Juveniles may be unable to gather the relevant information on conspecific performance since fledging is rather synchronous, and it may be too late for them to prospect afterward. The effect of PI availability to juveniles has been suggested in other birds, such as the highly synchronously breeding Bobolink (Dolichonyx oryzivo$r u s)$, in which adults may use PI in breeding site selection (Bollinger and Gavin 1989) but not juveniles, which use conspecific breeding density at the end of their birth year to make settlement decisions in the next year (Nocera et al. 2006). However, juvenile emigration probability was affected by Great Tit patch reproductive success or some correlate, with emigration increasing when heterospecific performance increased. This suggests that emigration may reduce interspecific competition because Great Tits are usually dominant over Blue Tits in competition for food and nest cavities (Perrins 1979, Wilson 1992). Thus the less competitive juveniles may be constrained by interspecific competition in their dispersal decisions. Combined with previous results (Doligez et al. 1999, 2002, 2004b), our results suggest that the greater importance of PI in habitat selection in adults than in juveniles may be a general phenomenon.

The immigration rate to different patches varied according to our manipulations of PI. Although we did not find differences in the immigration rates to different patches in response to the three treatments, immigration rates varied in a similar way in D and I compared to $\mathrm{C}$ patches. This may suggest that Blue Tits are insensitive to the inconsistency between the two components of PI (fledgling quality and quantity) that we manipulated. This may be because our manipulations caused a negative correlation between fledgling quantity and quality that does not exist naturally. This inconsistency between fledgling quantity and quality might not have been perceived or might have been ignored by animals so that a single high PI component, i.e., quantity or quality, was perceived as revealing high breeding patch quality and triggered immigration. However, the effect of our manipulations on immigration was fainter than on emigration. This may reveal differences in PI availability to emigrants and immigrants. As local breeders, emigrants have the opportunity to gather public information about their breeding patch during the whole breeding season. Time available to gather information and familiarity could lead them to be informed on the cue that is easiest to gather, that is fledgling quantity in local nests, which usually also means better juvenile quality in natural situations. Meanwhile at least some immigrants, such as breeders coming from distant patches and those coming from outside the population, apparently only had access to some components of public information in settlement patches after they finished breeding. Hence they may have been unable to assess fledgling quality in some nests either because fledglings had already left the nest or because local birds were more aggressive toward unfamiliar birds and did not allow them to access nests. In natural situations, immigrants might assess the number of juveniles still alive after a certain amount of time, a parameter that integrates the effect of both the number of fledglings that left the nests and their postfledging survival, which is negatively related to their 
body condition. In our experiment this number of surviving juveniles may have been similar in D and I patches and higher than in control patches.

Individuals must then gather and process subtle information (not only the number of chicks, but also their quality). Despite the fact that Blue Tits seemed to ignore the experimentally induced discrepancy between fledgling quantity and quality in the decreased and increased patches, our results show the complexity of the cognition involved in habitat choices. Fledgling quality could be revealed by several traits that are more readily assessable than fledgling mass. This is the case of gape, skin and plumage colorations, and fledgling activity, which are known to be used in parent-offspring communication (e.g., Heeb et al. 2003). We thus could expect them to be exploited also by prospectors. Our results suggest that they may be harder to assess in the context of breeding habitat choice. Alternatively, it may be that the natural variations of fledgling condition are not large enough to be used as a valuable cue of breeding habitat quality.

Despite the fact that we found that adult Blue Tits differentially use the two PI components depending on their status as residents in or immigrants to a patch, our results differ from those of Doligez et al. (2002) in the relative role of the two components of PI in emigration and immigration. While in Collared Flycatchers emigration was influenced by both fledgling quality and quantity and immigration was only influenced by the number of fledglings produced, the reverse is true in Blue Tits. We suggest that such a difference may be because the resident adult Blue Tits have a larger time window to gather components of PI (or some correlates) in various patches during the winter, while adult Flycatchers do not have enough time to gather such subtle information before migration. Therefore, PI use may vary according to the species' biological characteristics. In particular, such differences may find their origin in the type of environmental variation in which these species breed. More studies, and particularly multiple-year studies, are needed to elucidate the parameters that influence the respective role of these cues in breeding habitat choice.

The mechanism by which Blue Tits gather PI remains unknown. Adult Blue Tits may gather public information by visiting nest boxes occupied by conspecifics (Doligez et al. 2004a), observing the chick feeding activity at these nests (Pärt and Doligez 2003, Doligez et al. 2004a), or observing families around nests after fledgling. Blue Tit families remain together for a period of time after fledging and wander around their territories all together (Cramp and Perrins 1993). Therefore, these families would provide cues on the natal patch quality for some time after fledging. The recording of prospecting behavior on families outside the nests is difficult to do. However, we recorded some prospectors visiting conspecific active nests while observing feeding frequencies by Blue Tits. Concretely, we observed nine "prospecting at the nest entrance" events during 8030 - minute observations bouts at 46 different nests. As we focused on the nest entrance, we likely missed many prospecting events occurring from some distance from the nest entrance. Moreover, evidence for prospecting behavior linked to the gathering of PI has been found in two other cavity-nesting birds (the Collared Flycatcher [Pärt and Doligez 2003] and the Common Goldeneye [Bucephala clangula; Pöysa 2006]). Apart from these pioneering studies, prospecting behavior remains poorly documented (Reed et al. 1999).

\section{ACKNOWLEDGMENTS}

We thank all people who collaborated in data collection: I. Dworzynska, C. Loiseau, J. B. Mihoub, F. Moyenne, L. Pichegru, N. Silva, M. Xavier, and many others. J. M. Avilés provided useful comments on the manuscript. Two anonymous referees also provided very interesting suggestions for the manuscript. Bird capture and ringing were done under Ringing Licence (CRBPO Museum National d'Histoire Naturelle). Fieldwork was done under permission of Parc Naturel Régional de la Forêt d'Orient and French Office National des Forêts. This research work was partially supported by a Postdoctoral Marie Curie fellowship (contract HPMF-CT-2000-00716) to D. Parejo. During writing, D. Parejo was funded by the European Social Fund with an I3P contract in the CSIC. This project was funded by the French Ministère de l'Environnement (Convention GIP ECOFOR, contract number DRITT: C02178) and the UMR 7625 (Fonctionnement et Évolution des Systèmes Écologiques, Paris), as well as the GDR 2155 "Ecologie Comportementale."

\section{Literature Cited}

Bollinger, E. K., and T. A. Gavin. 1989. The effects of site quality on breeding-site fidelity in Bobolinks. Auk 106:584-594.

Boulinier, T., E. Danchin, J.-I. Monnat, C. Doutrelant, and B. Cadiou. 1996. Timing of prospecting and the value of information in a colonial breeding bird. Journal of Avian Biology 27:252-256.

Brown, C., M. B. Brown, and E. Danchin. 2000. Breeding habitat selection in Cliff Swallows: the effect of conspecific reproductive success on colony choice. Journal of Animal Ecology 69:133-142.

Clobert, J., E. Danchin, A. A. Dhondt, and J. D. Nichols. 2001. Dispersal. Oxford University Press, Oxford, UK.

Coolen, I., Y. van Bergen, R. L. Day, and K. N. Laland. 2003. Species difference in adaptive use of public information in sticklebacks. Proceedings of the Royal Society of London B 270:2413-2419.

Coolen, I., A. J. W. Ward, P. J. B. Hart, and K. N. Laland. 2005. Foraging nine-spined sticklebacks prefer to rely on public information over simpler social cues. Behavioral Ecology 16:865-870.

Cramp, S., and D. Perrins. 1993. Handbook of the birds of Europe, the Middle East and North Africa: the birds of the western Palearctic. Oxford University Press, Oxford, UK.

Danchin, E., T. Boulinier, and M. Massot. 1998. Conspecific reproductive success and breeding habitat selection: implications for the study of coloniality. Ecology 79:2415-2428.

Danchin, E., L. A. Giraldeau, T. J. Valone, and R. H. Wagner. 2004. Public information: from nosy neighbors to cultural evolution. Science 305:487-491.

Danchin, E., D. Heg, and B. Doligez. 2001. Public information and breeding habitat selection. Pages 243-258 in J. Clobert, E. Danchin, A. A. Dhondt, and J. D. Nichols, editors. Dispersal. Oxford University Press, Oxford, UK.

Deutsch, J. C. 1992. Olfactory cues influence female choice in 2 lek-breeding antelopes. Nature 356:596-598. 
Dhondt, A. A., B. Kempenaers, and J. Clobert. 1998. Sparrowhawk Accipiter nisus predation and Blue Tit Parus caeruleus adult annual survival rate. Ibis 140:580-584.

Doligez, B., E. Danchin, and J. Clobert. 2002. Public information and breeding habitat selection in a wild bird population. Science 297:1168-1170.

Doligez, B., E. Danchin, J. Clobert, and L. Gustafsson. 1999. The use of conspecific reproductive success for breeding habitat selection in a non-colonial, hole-nesting species, the collared flycatcher. Journal of Animal Ecology 68:1193-1206.

Doligez, B., T. Pärt, and E. Danchin. 2004a. Prospecting in the collared flycatcher: gathering public information for future breeding habitat selection? Animal Behaviour 67:457-466.

Doligez, B., T. Pärt, E. Danchin, J. Clobert, and L. Gustafsson. 2004b. Availability and use of public information and conspecific density for settlement decisions in the collared flycatcher. Journal of Animal Ecology 73:75-87.

Erwin, R. M., J. D. Nichols, T. B. Eyler, and D. B. Stotts. 1998. Modelling colony size dynamics: the metapopulation of Gullbilled Terns in coastal Virginia. Auk 115:970-978.

Giraldeau, L.-A., T. Valone, and J. J. Templeton. 2002. Potential disadvantages of using socially acquired information. Philosophical Transactions of the Royal Society of London B 357:1559-1566.

Greenwood, P. J. 1980. Mating systems, philopatry and dispersal in birds and mammals. Animal Behaviour 28: $1140-1162$.

Gros-Louis, J., D. J. White, A. P. King, and M. J. West. 2003. Female brown-headed cowbirds' (Molothrus ater) social assortment changes in response to male songs: a potential source of public information. Behavioral Ecology and Sociobiology 53:163-173.

Heeb, O., T. Schwander, and S. Faoro. 2003. Nestling detectability affects parental feeding preferences in a cavitynesting bird. Animal Behaviour 66:637-642.

Kendal, R. L., I. Coolen, and K. N. Laland. 2004. The role of conformity in foraging when personal and social information conflict. Behavioral Ecology 15:269-277.

Nocera, J. J., G. J. Forbes, and L.-A. Giraldeau. 2006. Inadvertent social information in breeding site selection of natal dispersing birds. Proceedings of the Royal Society of London B 273:349-355.

Nordell, S. E., and T. J. Valone. 1998. Mate choice copying as public information. Ecology Letters 1:74-76.

Parejo, D., and E. Danchin. 2006. Brood size manipulation affects frequency of second clutches in the Blue Tit. Behavioral Ecology and Sociobiology 60:184-194.
Parejo, D., E. Danchin, and J. M. Avilés. 2005. The heterospecific habitat copying hypothesis: can competitors indicate habitat quality? Behavioral Ecology 16:96-105.

Pärt, T., and B. Doligez. 2003. Gathering public information for habitat selection: prospecting birds cue on parental activity. Proceedings of the Royal Society of London B 270: 1809-1813.

Perrins, C. M. 1979. British tits. Collins, London, UK.

Pöysa, H. 2006. Public information and conspecific nest parasitism in goldeneyes: targeting safe nests by parasites. Behavioral Ecology 17:459-465.

Reed, J. M., T. Boulinier, E. Danchin, and L. W. Oring. 1999. Informed dispersal. Prospecting by birds for breeding sites. Pages 189-259 in V. J. Nolan, E. D. Ketterson, and C. F. Thompson, editors. Current ornithology. Kluer Academic/ Plenum Publishers, New York, New York, USA.

Serrano, D., and J. L. Tella. 2003. Dispersal within a spatially structured population of lesser kestrels: the role of spatial isolation and conspecific attraction. Journal of Animal Ecology 72:400-410.

Smith, R. D., G. D. Ruxton, and W. Cresswell. 2001. Patch choice decisions of wild blackbirds: the role of preharvest public information. Animal Behaviour 61:1113-1124.

Templeton, J. J., and L. A. Giraldeau. 1995. Patch assessment in foraging flocks of European starlings: evidence for the use of public information. Behavioral Ecology 6:65-72.

Templeton, J. J., and L. A. Giraldeau. 1996. Vicarious sampling: the use of personal and public information by starlings foraging in a simple patchy environment. Behavioral Ecology and Sociobiology 38:105-114.

Valone, T. J., and J. J. Templeton. 2002. Public information for the assessment of quality: a widespread social phenomenon. Philosophical Transations of the Royal Society of London B 357:1549-1557.

van Bergen, Y., I. Coolen, and K. N. Laland. 2004. Nine-spined sticklebacks exploit the most reliable source when public and private information conflict. Proceedings of the Royal Society of London B 271:957-962.

Wagner, R. H., and E. Danchin. 2003. Conspecific copying: a general mechanism of social aggregation. Animal Behaviour 65:405-408.

Ward, M. P. 2005. Habitat selection by dispersing yellowheaded blackbirds: evidence of prospecting and the use of public information. Oecologia 145:650-657.

Wilson, J. D. 1992. Correlates of agonistic display by Great Tits Parus major. Behaviour 121:168-214. 